\title{
Ethno medicinal, phytochemical and pharmacological aspects of solanum incanum (lin.)
}

\author{
John K. Mwonjoria ${ }^{1}$, Joseph J. Ngeranwa ${ }^{1}$, Helen N. Kariuki ${ }^{2}$, Charles G. Githinji ${ }^{2}$, \\ Micah N. Sagini ${ }^{3}$, Stanley N. Wambugu ${ }^{4}$ \\ ${ }^{1}$ Department of Biochemistry and Biotechnology; Kenyatta University \\ ${ }^{2}$ Department of Medical Physiology; University of Nairobi \\ ${ }^{3}$ Heidelberg University; Germany \\ ${ }^{4}$ Department of Veterinary Anatomy and Physiology; University of Nairobi \\ *Corresponding author E-mail: jkmmaina@gmail.com
}

\begin{abstract}
Solanum incanum is used in Africa and other parts of world as a folklore remedy for various ailments that include; sore throat, angina, stomach ache, ear inflammation, snake bites, wounds, liver disorders, skin ailments (ringworm), warts, inflammatory conditions, painful periods and fever.

Phytochemical studies of this herb indicate that it contains substances such as steroidal alkaloids, glyco-alkaloids, antioxidants (flavonoids and chlorogenics), saponins and even carcinogenic substances. The herbal extract posses' antinociceptive, antipyretic, antispasmolytic, orexic, anorexic, hypoglycemic, antimicrobial, anti-schistosomal, anti-fungal, and anti-cancer activity.

The herb is therefore likely to be a major source of novel, affordable and effective therapeutic substances against myriad ailments afflicting people in the world.

This review explores the phyto-pharmacological effects of the S. incanum and compiles vital information that may assist researchers on what is known about this herb and gaps for further investigation.
\end{abstract}

Keywords: Anticancer, Antimicrobial, Antinociceptive, Antipyretic, Solanum Incanum.

\section{Introduction}

Solanum incanum or Sodom/bitter apple (English), entulele (Maasai), mtula (Swahili) is a perennial, wild shrub like herb that belongs to Solanaceae family which grows in many regions of Africa, Middle East and Far East Asia. It is an erect or spreading perennial shrub with leaves and stem occasionally having small prickles. The fruits are small berries of $2-3 \mathrm{~cm}$ in diameter and yellowish orange or brown in color when ripe (Matu 2008). Controversy surrounds the name of this plant because it was given different descriptions by different authors that vary widely (Anaso \& Ouzo 1990). In Africa the herb is used as a folklore remedy for sore throat, angina, stomach-ache, colic, headache (Kokwaro 1993, Dold \& Cocks 2000) and in wounds (Bussmann et al. 2006). Other uses include; relieve of painful menstruation, liver problems and pain caused by onchocerciasis, pleurisy, pneumonia and rheumatism. The plant parts are also widely used to alleviate skin problems, such as infections, whitlow, ringworm, burns, sores, rashes, wounds, warts, carbuncles, ulcers, inflammations and benign tumors. In West Africa, leaves are eaten or added to soup to improve flavor, while fruits are used as vegetables. Alternatively, the roots are chewed or its infusions applied externally on scarifications. Similarly, decoctions derived from leaves, roots and fruits are either gargled or drunk. Leaf parts are also used for washing painful areas, while in some cases they are burnt and the ash mixed with fat for use as an ointment. Conditions in which the various plant parts are used by different African communities include, pain relieve in toothache and as a cure for snake bites and sexually transmitted disease. It is also used as an ingredient of arrow poison, as spice to improve flavor and as well as in curdling milk or in cheese making. In Ethiopia it is used in leather tanning and soap making (Matu 2008).

\section{Photochemistry}

Table1: Shows some phytochemicals isolated from $\mathrm{S}$. incanum

\begin{tabular}{|c|c|c|}
\hline S/No. & Chemical Name & $\begin{array}{l}\text { Chemical } \\
\text { formula }\end{array}$ \\
\hline 1. & Incanumine (Lin et al. 1990) & $\mathrm{C}_{49} \mathrm{H}_{79} \mathrm{NO}_{19}$ \\
\hline 2. & Solasodine (Lin et al. 1990) & $\mathrm{C}_{27} \mathrm{H}_{43} \mathrm{NO}_{2}$ \\
\hline 3. & Carpesterol (Lin et al. 1990) & $\mathrm{C}_{37} \mathrm{H}_{54} \mathrm{O}_{4}$ \\
\hline 4. & $\beta$-Sitosterol (Lin et al. 1990) & $\mathrm{C}_{29} \mathrm{H}_{50} \mathrm{O}$ \\
\hline 5. & Stigmasterol(Lin et al.1990) & $\mathrm{C}_{35} \mathrm{H}_{58} \mathrm{O}_{6}$ \\
\hline 6. & Khasianine (Lin et al. 1990) & $\mathrm{C}_{39} \mathrm{H}_{63} \mathrm{NO}_{11}$ \\
\hline 7. & Adenosine (Yun-lian et al. 2000) & $\mathrm{C}_{10} \mathrm{H}_{13} \mathrm{~N}_{5} \mathrm{O}_{4}$ \\
\hline 8. & $\begin{array}{l}\text { Kaempferol 3-O-b-D glucopyranosyl (1@2)-b- } \\
\text { D-glucopyranoside (Yun-lian et al. 2000) }\end{array}$ & $\mathrm{C}_{27} \mathrm{H}_{30} \mathrm{O}_{16}$ \\
\hline 9. & $\begin{array}{l}\text { Quercetin3-O-b-D-glucopyranosyl (1®2)-b-D- } \\
\text { glucopyranoside (Yun-lian et al. 2000) }\end{array}$ & \\
\hline 10. & Kaempferol (Yun-lian et al. 2000) & $\mathrm{C}_{15} \mathrm{H}_{10} \mathrm{O}_{6}$ \\
\hline 11. & Chlorogenic acid (Yun-lian et al. 2000) & $\mathrm{C}_{16} \mathrm{H}_{18} \mathrm{O}_{9}$ \\
\hline 12. & $\begin{array}{l}\text { Benzyl O-b-D-xylopyranosyl (1@2)-b-D- } \\
\text { glucopyranoside (Yun-lian et al. 2000) }\end{array}$ & $\mathrm{C}_{58} \mathrm{H}_{94} \mathrm{O}_{26}$ \\
\hline 13. & Quercetin (Yun-lian et al. 2000) & $\mathrm{C}_{15} \mathrm{H}_{10} \mathrm{O}_{7}$ \\
\hline 14. & Astragalin (Yun-lian et al. 2000) & $\mathrm{C}_{21} \mathrm{H}_{20} \mathrm{O}_{11}$ \\
\hline 15. & Isoquercitrin (Yun-lian et al. 2000) & $\mathrm{C}_{21} \mathrm{H}_{20} \mathrm{O}_{12}$ \\
\hline 16. & Protocatechuic acid (Yun-lian et al. 2000) & $\mathrm{C}_{7} \mathrm{H}_{6} \mathrm{O}_{4}$ \\
\hline
\end{tabular}




\begin{tabular}{|c|c|c|}
\hline 17. & trans-p-coumaric acid (Yun-lian et al. 2000) & $\mathrm{C}_{9} \mathrm{H}_{8} \mathrm{O}_{3}$ \\
\hline 18. & $\begin{array}{l}\text { Luteolin 7-O-b-D-glucopyranoside (Yun-lian } \\
\text { et al. 2000) }\end{array}$ & $\mathrm{C}_{21} \mathrm{H}_{20} \mathrm{O}_{11}$ \\
\hline 19. & $\begin{array}{l}\text { Isorhamnetin 3-O-b-D-glucopyranoside (Yun- } \\
\text { lian et al. 2000) }\end{array}$ & $\mathrm{C}_{22} \mathrm{H}_{22} \mathrm{O}_{12}$ \\
\hline 20. & Caffeic acid (Yun-lian et al. 2000) & $\mathrm{C}_{9} \mathrm{H}_{8} \mathrm{O}_{4}$ \\
\hline 21. & Baicalin (Yun-lian et al. 2000) & $\mathrm{C}_{21} \mathrm{H}_{18} \mathrm{O}_{11}$ \\
\hline 22. & $\begin{array}{l}\text { Kaempferol 3-O- }\left(6^{2} \phi-O-2,5-\right. \\
\text { dihydroxycinnamoyl)-b-D-glucopyranosyl } \\
(1 \circledast 2) \text { b- D glucopyranoside (Yun-lian et al. } \\
2000)\end{array}$ & $\mathrm{C}_{36} \mathrm{H}_{36} \mathrm{O}_{19}$ \\
\hline 23. & Solasonine (Eltayeb et al. 1997) & $\mathrm{C}_{45} \mathrm{H}_{73} \mathrm{NO}_{16}$ \\
\hline 24. & Solamargine (Eltayeb et al. 1997) & $\mathrm{C}_{45} \mathrm{H}_{73} \mathrm{NO}_{15}$ \\
\hline 25. & Diosgenin(Matu 2008) & $\mathrm{C}_{27} \mathrm{H}_{42} \mathrm{O}_{3}$ \\
\hline 26. & Yamogenin (Matu 2008) & $\mathrm{C}_{27} \mathrm{H}_{42} \mathrm{O}_{3}$ \\
\hline 27. & Dimethylnitrosamine (Matu 2008) & $\mathrm{C}_{2} \mathrm{H}_{6} \mathrm{~N}_{2} \mathrm{O}$ \\
\hline 28. & Vitamin $B_{2}$ (Auta \&Ali 2011) & $\mathrm{C}_{17} \mathrm{H}_{20} \mathrm{~N}_{4} \mathrm{O}_{6}$ \\
\hline 29. & Vitamin C (Auta \& Ali 2011) & $\mathrm{C}_{6} \mathrm{H}_{8} \mathrm{O}_{6}$ \\
\hline
\end{tabular}

Table 2: Shows a list of some minerals found in S. incanum and their respective concentrations in ashes.

\begin{tabular}{lll}
\hline S/No. & Name of the ions & $\begin{array}{l}\text { Concentration parts per million } \\
(\mathrm{pmm})\end{array}$ \\
\hline 1. & Sodium (Auta \& Ali 2011) & 3.81 \\
2. & Potassium (Auta \& Ali & 1.58 \\
3. & Zinc (Auta \& Ali 2011) & 3.91 \\
4. & Copper (Auta \&Ali 2011) & 2.10 \\
5. & $\begin{array}{l}\text { Cadmium (Auta \& Ali } \\
\text { 2011) }\end{array}$ & 1.19 \\
6. & Chromium (Auta \& Ali & 1.60 \\
\hline
\end{tabular}

\section{Pharmacological activity}

\subsection{General Uses}

Solasodine is used commercially as precursors for the production of steroidal compounds for medicinal use particularly as contraceptives (Matu 2008).

\subsection{Anti-microbial and antifungal effects}

Previous reports indicate that the water soluble crystals derived from unripe fruits of $\mathrm{S}$. incanum exhibited marked broad spectrum antibacterial effect on several gram positive and gram negative bacteria such as Streptococcus pyogenes, Staphylococcus aureus, Clostridium perfringens, Bacillus anthracis, Brucella arbutus and Salmonella species. It also inhibited a number of fungi like Microsporum species, Trichophyton tonsurans, Cryptococcus neoformans, Candida albicans etc. Exposure of these fungi to Solanum extract distorted the hyphae and inhibited sporulation which may suggest that either $S$. incanum extract inhibited a vital cellular pathway or act as an anti-metabolite (Mbaya \& Muhammed 1976). Ethanol extract of S. incanum fruit exhibited potent antibacterial effect (Alamri \& Moustafa 2012), while leaf extracts showed antimicrobial activity against the Escherichia coli (Britto \& Senthinkumar 2001), Streptococcus pyogenes, Staphylococcus aureus, and Pseudomonas aeuruginosa (Taye et al. 2011). In a study to investigate the herbs anti-schistosomal effects using methanol and aqueous extracts, the former took the shortest time to kill cercariae compared to aqueous group (Muchika et al. 2011).

\subsection{Antipyretic effects}

In a study conducted to evaluate the antipyretic effect of the herb, an intraperitonial injection of 50 and $100 \mathrm{mg} / \mathrm{kg}$ doses of diclomethane/methanol root extract of the $\mathrm{S}$. incanum exhibited significant antipyretic effect on endotoxic induced fever in rats. The anti-pyressis was comparable to that of $100 \mathrm{mg} / \mathrm{kg}$ of aspirin (Mwonjoria et al. 2011). On this basis, it is highly probable that the plant contains compound(s) with antipyretic effect.

\subsection{Antinociceptive effects}

Solanum incanum root extract was also found to possess analgesic effect. In this study, CBA mice were injected with 100 , and 200 $\mathrm{mg} / \mathrm{kg}$ of the diclomethane/methanol extract of the $\mathrm{S}$. incanum root. In the tail flick test, the 100 and $200 \mathrm{mg} / \mathrm{kg}$ doses of the extract exhibited significant antinociceptive effect that was comparable to that of aspirin. Similar results were obtained in the hot plate test (Mwonjoria et al. 2011). Both tail flick and hotplate test responses are integrated in the centrally nervous system. The tail flick response is integrated at the spinal cord level while integrated response of the hot plate occurs in a supra-spinal region (Le Bars et al. 2001). Therefore, the $S$. incanum extract may have exerted the antinociceptive effect via both spinal and supra-spinal integrated mechanisms.

\subsection{Hypoglycemic and an-orexic effects}

In an experiment to investigate the effects of S. incanum root and fruit extracts on blood sugar, the fruit extract lowered the blood glucose levels and appetite in rats. The sugar lowering effects were comparable to those of metformin or glibenclaride. However, the root extract increased the food intake in addition to decreasing the blood glucose levels. The rats also developed diarrhea. In the two cases, the insulin level remained unaffected implying that the observed hypoglycemia may have been due to either anorexia or reduction in glucose absorption (Musabayane et al. 2006). The juice obtained by chewing or squeezing $S$. incanum leaves significantly reduced the postprandial glucose surge in normoglycemic humans (Uchenna et al. 2009)

\subsection{Insect repellant properties}

Chlorogenic acid has antioxidant and insect repellent properties and retards growth and development when ingested by insects (Matu 2008).

\subsection{Spasmolytic effects}

The spasmolytic activity of aqueous root extract of S. incanum was assessed on contractions of isolated guinea pig ileum, induced by acetylcholine, and compared with the effect of atropine a nonspecific anti -cholinergic drug. The aqueous root extract of $\mathrm{S}$. incanum inhibited the response to acetylcholine in a concentration-dependent manner similar to atropine. The extract inhibited charcoal travel in mice intestine by $36.28,51.45,52.93$ and 38.53 percent in doses of 50,100, 200 and $400 \mathrm{mg} / \mathrm{kg}$ body weight respectively (Assefa et al. 2006).

\subsection{Anticancer effects}

Solanum species have been used in many parts of the world for treatment of tumors for a long time. One of the earliest reports on anti-tumor effect of the species was by Kupchan and others who demonstrated that the crude extract of S. dulcamara inhibited sarcoma in mice (Kupchan et al. 1965). Solamargine, an alkaloid from $\mathrm{S}$. incanum has been shown to disrupt phosphatidylcholine or cholesterol liposomes (Roddick et al. 1990) and was also reported to possess a potent cytotoxicity to human hepatocytes (Hep3B) and normal skin fibroblast by apoptosis through the up-regulation of tumor necrosis factor receptor-1 (TNFR-1) expression (Hsu et al. 1996). Similarly, solamargine triggered apoptosis in human hepatoma cells besides elevating the level of TNFR-1 and 2 on the hepatoma cells. These effects were neutralized with TNFR-1and 2 specific antibodies (Kuo et al. 2000) Solamargine was found to induce the HA549 lung adenocarcinoma cell apoptosis. In this study, the compound caused morphological changes in chromatin condensation, DNA fragmentation and sub-G (1) peak in a DNA histogram of A549n cells. It 
also elevated the TNFR-1 and 2 expression thereby overcoming the resistance to TNF $\alpha$ and $\beta$ besides, sensitizing the tumor cells through TNFRs and mitochondrial mediated pathways which may indicate that it has a potential against TNFs and Cisplatin resistance lung cancer cells (Chia-Hua et al. 2004). In addition the alkaloid induced several apoptotic processes such as release of cytochrome $\mathrm{C}$ from the mitochondria, down regulation of antiapoptotic $\mathrm{Bcl} 2$ and Bcc-xL, it also increased the levels of caspace3 activity and DNA fragmentation (Zhou et al. 2008). Another study involving the use of cell lines indicated that solamargine modulated TNFR and Tumor necrotic factor receptor-1 associated death domain protein / Fas-associated protein with death domain (TRADD/FADD) signaling pathway and enhanced binding of TNF $\alpha$ and $\beta$ to lung cancers cells. Additionally, it triggered the intrinsic resistant cancer cells to become susceptible to TNF $\alpha \& \beta$ Other effects included enhanced release of cytochrome $c$, down regulation of anti-apoptotic $\mathrm{Bcl}-2$ and $\mathrm{Bcl}-\mathrm{xL}$, elevation of caspasce-3 activity and DNA fragmentation (Li-Feng et al. 2004). The drug resistance and poor prognosis encountered in breast cancer correlates with over expression of Human epidermal growth factor (HER2/neu) receptor expression (Ross \& Fletcher, 1998 and Weiya et al. 2004). However, solamargine modulated the HER2/neu gene of HER2/neu high expressing human cell line ZR-72-1. It also decreased the number of HER2/neu receptors in highly HER2/neu expressing breast cancer cells. A combination of solamargine with methotrexate, 5-flurouracil or cisplatin increased the susceptibility of breast cancer cells expressing high levels of HER2/neu (Shiu et al. 2008). In breast cancer, solamargine was found to induce apoptosis by up regulating the expression of external death receptors such as TNFR-1, Fas, TNFR-1- associated death domain (FADD) and activated mitochondrial mediated death pathway by enhancing the intrinsic ratio of $\mathrm{Bax}$ to $\mathrm{Bcl}-2$. The latter effect involved up regulation of Bax and down regulation of Bcl-2 and Bcl-xL expression resulting in release of mitochondrial cytochrome- $\mathrm{C}$ and activation of caspace- 9 and -3 in the cell. Cisplastin anticancer cells apoptotic activity is associated with caspace -8/-3 and Bax /cytochrome c pathways. However, resistance to Cisplastin correlates with $\mathrm{Bcl}-2$ and $\mathrm{Bcl}-\mathrm{xL}$ over expression (Michaud et al. 2009), which is suppressed by solamargine (Shiu et al. 2007).

Solamargine rapidly induce acute cell injury and bursting tumor cells by damaging the cell membrane in Human K562 leukemia and squamous cell carcinoma KB cells. This cytotoxic effect did not correlate with the expression of multidrug resistance and was triggered rapidly by the $50 \mu \mathrm{g}$ dose of the alkaloid. It also caused a rapid absorption of propidium iodide, release of lactate dehydrogenase and leakage of cytoplasmic contents which indicates that the cytotoxicity might have involved plasma membrane disruption. The alkaloid also rapidly induced membrane blebbing which could not be prevented by chelating either the intracellular or extracellular calcium ions though it was inhibited by some polyethylene glycols. It also disrupted the cytoplasmic actin and microtubules (Sun et al. 2011).The alkaloid also killed the MDR sub-lines namely the human myelogenous leukemia K562 cell line and its multidrug - resistant counterpart K562/A02, squamous cell carcinoma KB parental cell lines the VCR-selected MDR KB/VCR sub-line, the human NSCLC H460 cells and its multidrug- resistant counterpart H460/paclitaxel (Taxol) (Xia et al. 2011). Solamargine is also shown to induce pro-apoptotic effects in MDR K562/A02 cells lines by down regulating MDR1 mRNA and decreasing the mRNA expression of P-glycoprotein and actin in the cells (Xia et al. 2011, Ding et al. 2012). In another study, Solamargine obtained from S. nigrum induced apoptosis in $\mathrm{Hu}-$ man squamous cell carcinoma cell lines by up-regulating the TNFRs, Fas and some of the adaptors associated with the signaling cascade. In addition, it also activated the mitochondrial apoptotic pathway and cleared the papillomas in hairless mice within 10 weeks (Chia-Hua et al. 2004). Flavonoids are a potent antioxidants and free radical scavengers which prevent oxidative cell damage (Salah et al. 1995). The herb also contains vitamin $\mathrm{B}_{2}, \mathrm{C}$ (a major water-soluble anti-oxidant in extracellular fluid) and vitamin $\mathrm{E}$ a major lipid soluble anti-oxidant that prevents peroxidation (Auta \& Ali 2011).

\subsection{Toxicity}

The highest concentration of the alkaloid is found in the smallest leaves of S. incanum while the roots and stem were initially shown to have similar concentration of the alkaloid (Eltayeb et al. 1997). The fruits contain dimethylnitrosamine, a potent carcinogen that may be associated with high incidence of esophageal cancer in areas of Africa where the fruit sap is used to curdle milk. Similarly, extracts of the fruits has been found to cause skin cancer in animals. The unripe fruits of S. incanum were found to exhibited toxic effects in goats (Thaiya et al. 2010).However, oral administration of up to $15,000 \mathrm{mg} / \mathrm{kg}$ doses of the extract to mice did not show signs of conventional toxicity (Assefa et al. 2006)

\section{Conclusion}

S. incanum has been used as folklore remedy for various ailments afflicting people in various parts of the world for a long time. However, research interest to evaluate its therapeutic potential has developed recently perhaps on realization that this herb may contain novel chemicals that exhibit a wide range of pharmacological effects. The anticancer effect of this herb is currently under intensive research with much interest focusing on Solamargine. With rising cases of cancer mortality globally, more research is required to establish the mechanism through which this phytochemicals induces apoptosis and its potential in developing a safe and effective drug for various types of cancer. Nevertheless, with the exception of anticancer effects, little or no attempt has been made to elucidate the modes of action of a wide range of pharmacological effects associated with this herb. Therefore, more studies are required on the alkaloids and other phytochemicals of this herb.

\section{Acknowledgement}

Acknowledgement; the authors would like to thank Mr Kedera Victor of Kenyatta University for the technical assistance during the typing of the manuscript.

\section{References}

[1] Alamri SA and Moustafa .F (2012), Antimicrobial properties of 3 medicinal plants from Saudi Arabia against some clinical isolates of bacteria, Saudi Med. J. 33(3) (272-277.

[2] Anaso H U and Ouzo (1990), Relationship and Classification among Solanum incanum Complex, Cytologia (55) 1-14.

[3] Assefa A, Urga K, and Guta A, et al. (2006), Spasmolytic Activity of the Aqueous Root Extract of Solanum incanum, Solanaceae., Ethiop J Biol Sci (5) 2 .

[4] Auta R and Ali I (2011), Nutritional and chemical value of Solanum incanum (bitter garden egg), Intern. J. Trop. Med. Pub. Health 1(1) 96-107.

[5] Britto SJand Senthinkumar S (2001), Antimicrobial activities of Solanum incanum leaf extract, Asian J. Microbio. Biotechn. Environ. Sci. 3(1-2) 65-66.

[6] Bussmann RW, Gilbreath GG, Solio J, et al. (2006), Plant use of the Maasai of Sekenani valley Maasai Mara, J. Ethnobiol. And Ethnomed. (2) 22.

[7] Chia-Hua L, Li-Feng L, Li-Yen S, Yu-Sheng H, Li-Ching C,.KouWha K (2004), Action of solamargine on TNFs \& cisplatin-resistant human lung cancer cells, Biochem Biophys Res. comm. 322(3)751758.

[8] Ding X, Zhu F, Li min, Gao S (2012), Induction of apoptosis in human hepatoma SMMC-7721 cells by solamargine from Solanum nigrum, J. Ethnopharm. 139(2) 599- 604.

[9] Dold A P and Cocks ML (2000), The medical use of some weeds, problem and alien plants in the Graham's town and Peddie district of Eastern Cape S.A, S. A. J. Sci. 96467- 473. 
[10]Eltayeb EA, Al-Ansari, Roderick JG (1997), Changes in steroidal alkaloid Solasodine during development of Solanum nigrum \& Solanum incanum, Phytochemistry 46(3) 489- 494.

[11]Hsu SH, Tsai SH, Lin CN, Yen MH, Kuo KW (1996), Solamargine purified from Solanum incanum Chinese herb triggers gene expression of human TNFR I which may lead to cell apoptosis, Biochem. Biophys. Res. Comm. 229(1) 1-5.

[12]Kokwaro J O (1993), Medicinal plants of East Africa, $2^{\text {nd }}$ Edition East Africa Literature Bureau, Nairobi, 222-223.

[13]Kupchan SM, Barbouti ST, Knox JK, Laucam CA (1965), BetaSolamarine; tumour inhibitor isolated from Solanum dulcamara, Science 150(3705) 827-1828.

[14]Kuo KW, Hsu SH, LiYP, et al. (2000), anticancer activity evaluation of the Solanum glycoalkaloid solamargine. Trig gering apoptosis in human hepatoma cells, Biochem. Pharmacology 60(12) 865-73.

[15]Le Bars D, Gozariu Mand Caddens (2001), Animal model of nociception, Pharmacol. Rev. (53) 597-652.

[16]Lin C, Lu C, Cheng M, Gan K, Won S (1990), The Cytotoxic principles of Solanum incanum, Natural Prod. 53(2) 513-16.

[17]Li-Feng L, Chia-Hua L, Shiu L, Wei-Ling L, Chih-Chao L, Kou-Wha K (2004), Action of solamargine on human lung Cancer cells-enhancement of the susceptibility of cancer cells to TNFs, FEBS Letters 577(1-2) 67-74.

[18]Matu E.N (2008), Solanum incanum L, PROTA (Plant Resources of Tropical Africa), Wageningen Netherlands, Protabase.

[19]Mbaya B and Muhammed S (1976), Antibiotic action of Solanum incanum L., Anti-microb. Agents Chemother. (6) 920-927.

[20]Michaud WA, Nichols AC, Mrozl EA et al. (2009), Bcl-2 blocks cisplatin-induced apoptosis and predicts poor outcome following chemoradiation treatment in advanced oropharyngeal squamous cell carcinoma, Clin. Cancer Res. 15(5) 1645-54.

[21]Muchika S, Kutima HL, Maranga RO and Yole DS (2011), An tischistosomal effects of Solanum incanum and Carica pa paya crude extracts on the parasite Schistosoma mansoni invivo and in vitro, Intern. J. Trop. Med. (7) 2.

[22]Musabayane CT, Bwititi, PT and Ojewole JA (2006), Effects of oral administration of some herbal extracts on food consumption and blood glucose levels in normal and strepto zotocin-treated diabetic rats, Methods find Exper. Clin Pharmacol. 28(4) (223-228.

[23]Mwonjoria, JK, Kariuki H and Waweru FN (2011), the antinociceptive antipyretic effects of Solanum incanum (Lin.) in animal models, Intern. J. Phytopharm. 2(1) 22-26.

[24]Roddick JG, Rijneberg AL,Weissenberg M (1990), Membrane disrupting properties of the steroidal glycoalkaloids solasomine and solamargine, Phytochemistry 29(5) 1513-1518.

[25]Ross JS and Fletcher A (1998), The HER-2/neu oncogene in breast cancer: prognostic factor, predictive factor, and target for therapy, Stem cells 16(6) 413-28.

[26]Salah W, Miller NJ, Pagauga G et al. (1995), Polyphenolic flavornols as scavenger of aqueous phase radicals and Chain breaking antioxidants, Arch. Biochem. Bio. 2 339-346.

[27]Shiu LY, Chang LC, Liang CH, Huang YS, Sheu HM, and Kuo KW (2007), Solamargine induces apoptosis and sensitizes breast cancer cells to cisplatin, Food chem. Toxic. 45(11) 2155-2164.

[28]Shiu LY, Liang CH, Huang YS, Sheu HM, Kuo KW (2008), down regulation of Her2/neu receptor by solamargine en hances anticancer drug-mediated cytotoxicity in breast cancer cells with high expressing Her2/neu, Cell Biol. Toxic. 24(1) 1-10.

[29]Sun L, Zhao Y, Yuan H, Li X, Cheng A, Hongxiang L (2011), Solamargine, a steroidal alkaloid glycoside, induces oncosis in human K562 leukemia and squamous cell carcinoma KB cells, Cancer Chemother. Pharm. 67(4) 813-821.

[30]Taye B, Giday M, Animut A, Seid A (2011), Antimicrobial activity of selected plants in traditional treatment of wounds in Ethiopia, Asian Pacific J. Trop. Bio Med. 370- 375

[31]Thaiya AG, Nyaga PN, Maribei,JM, Nduati D, Mbuthia PG and Ngatia TA (2010), Experimental Solanum incanum L. poisoning in goats [abstract], Bull. Animal Health Prod. Africa (58) 1.

[32]Uchenna OV, Chinwe OE, Ijeoma EO, Ezenduka PO (2009) Investigation of the effect of Solanum incanum on postprandial blood glucose concentration of normoglycemic Nigerians, Pakistan J Nutri. (8) $1631-1635$

[33]Weiya XC, Jin-Shing, X, Zhou et al. (2004), Phosphorylation / cytoplasmic localization of p21Cip1/WAF1 is associated with her2/neu over- expression and provides a novel combination predictor for poor prognosis in breast Cancer patients, Clin. Cancer Res. (10) 3815 3824.

[34]Xia L, Zho Y, Mei J, Liu S, CUI min, Lou Hong X (2011), Induction of actin disruption and down regulation of P-glycoprotein expression by solamargine in multiple drugs resistant K562/A02 cells, Chin. Med. J. 124(13) 2038-2044.

[35] Yun-lian L, Wan-yi W, Kuo YH (2000) Non-steroidal constituents from Solanum incanum, Chin. Chem. Soc. (47) 247- 251.

[36]Zhou Y, Gao W, Likenfeng (2008), Chinese herbal medicine in treatment of liver cancer, Asian J Trad. Med. (1) 1-11. 